\title{
Can a decrease of laboratory-confirmed influenza A after school closure be extrapolated to SARS-CoV-2?
}

Andres Perez-Lopez ${ }^{1}$, Mohammad Hasan ${ }^{1}$, Muhammad Iqbal Iqbal ${ }^{1}$, Mohammed Janahi ${ }^{1}$, Diane Roscoe ${ }^{1}$, and Patrick Tang ${ }^{1}$

${ }^{1}$ Sidra Medical and Research Center

June 11, 2020

\section{Hosted file}

Influenza activity as a COVID-19 proxy.docx available at https://authorea.com/users/332118/ articles/458576-can-a-decrease-of-laboratory-confirmed-influenza-a-after-school-closurebe-extrapolated-to-sars-cov-2 